Check for updates

Stockholm

Cite this as: BMJ 2021;375:n2477 http://dx.doi.org/10.1136/bmj.n2477 Published: 11 October 2021

\section{Covid-19: Sweden, Norway, and Finland suspend use of Moderna vaccine in young people "as a precaution"}

\author{
Marta Paterlini
}

Sweden, Norway, and Finland suspended the use of Moderna's covid-19 vaccine on 7 October after reports of possible rare side effects.

The pause "for precautionary reasons" in Sweden and Finland concerns anyone born 1991 or later. In Finland, under 30 will now be offered the Pfizer vaccine as their second dose. Swedish officials are still discussing the second dose for the 81000 under 30 s who received a first dose of Moderna.

In Norway officials have suspended the use of Moderna's vaccine in those under 18, advising that they are offered the Pfizer vaccine instead.

At a press conference on 6 October Anders Tegnell, epidemiologist at the Swedish Public Health Agency, explained that the suspension of the Moderna vaccine followed the detection of signals of an increased risk of side effects such as myocarditis and pericarditis.

Myocarditis is a rare side effect of all mRNA vaccines, especially in boys and young men and mainly after the second dose. Data indicate that this occurs more often after the Moderna vaccine than Pfizer's. This seems to apply regardless of which vaccine was given as the first dose.

Sweden's decision will be reconsidered on 1 December. Tegnell added that those who have been vaccinated recently, with their first or second dose of the Moderna vaccine, do not need to be concerned, "nevertheless it's good to know what symptoms they need to be vigilant about," he said.

Mika Salminen, director of the National Institute for Health and Welfare in Finland, told The BMJ, "Nordic countries provide unique opportunities for joint health registry based research in large populations with long and complete follow-up, facilitated by shared features. They have come together to detect and investigate rare side effects."

"The Nordic registry study looking at the incidence of myocarditis and pericarditis has not been completed-and therefore hasn't been published and final conclusions cannot be drawn," he said.

The signals detected in the Nordic countries have been passed to the European Medicines Agency (EMA). A spokesperson for the agency told The BMJ, "Further evaluation of the data are required. EMA's safety committee (PRAC) will assess the new data to determine whether there is a need to update current advice in the product information for the vaccines."

In July 2021, PRAC concluded ${ }^{1}$ that myocarditis and pericarditis can occur in very rare cases following vaccination with both mRNA vaccines, more often after the second dose and in younger men. The committee recommended listing myocarditis and pericarditis as side effects in the product information for these vaccines and published a warning to raise awareness among healthcare professionals and people who have received these vaccines.

Nordic authorities emphasised that the risk of being affected by myocarditis or pericarditis is very small and that covid-19 is far more dangerous.

A misunderstanding in communication led several media outlets to report that Denmark had also suspended the use of the Moderna vaccine, but the Danish Public Health Agency said it has not seen an increase in cases of myocarditis and was continuing to use both mRNA covid-19 vaccines. ${ }^{2}$

Seven days in medicine: 7-13 July 2021. BMJ2021;374:n1772.pmid: 34266860

www.sst.dk/da/Nyheder/2021/SST-fortsaetter-med-at-vaccinere-boern-og-unge-under-18-aar-med-COVID-19-vaccinen-fra-Pfizer-Bion. 